\title{
EDUCAÇ̃̃O AMBIENTAL DIALÓGICO-CRÍTICA COM COMUNIDADES TRADICIONAIS NO PANTANAL DE MATO GROSSO: A SOLIDARIEDADE E OS ENFRENTAMENTOS NAS PRÁTICAS SOCIAIS ${ }^{1}$
}

\author{
Silvano Carmo de Souza ${ }^{2}$, Amadeu José Montagnini Logarezzi ${ }^{3}$
}

\begin{abstract}
RESUMO
Nesta pesquisa de educação ambiental dialógico-crítica realizada no Pantanal em Cáceres-MT dialogamos, durante dois anos, com pescadoras/es tradicionais. A partir do referencial teóricometodológico freiriano e habermasiano, objetivamos identificar e problematizar quais são os elementos obstaculizadores (processos de colonização do mundo da vida) e transformadores (processos de resistência e enfrentamento à colonização) que dizem respeito à prática da pesca profissional artesanal. Identificamos, dialogicamente, que decorrem destas práticas sociais pantaneiras processos educativos libertadores, de anúncio e denúncia permanentes, fundados em uma solidariedade interna, característica da ética tradicional ribeirinha pantaneira. Também, notamos que pesquisas de educação ambiental embasadas em valores, práticas e conceitos dialógico-críticos potencializam a coordenação de ações.
\end{abstract}

Palavras-chave: Educação ambiental dialógico-crítica. Educação ambiental no Pantanal. Educação ambiental com comunidades tradicionais no Pantanal. Aprendizagem dialógica. Metodologia comunicativo-crítica.

\begin{abstract}
This research of environmental education dialogical- critical realized at Pantanal in Cáceres-MT. We dialogued throughout two years with traditional fishermen and fisherwomen.. From the referential methodological-theoretical based on Freire and Habermas theories. We objectify to identify and problematize which are the obstacles elements (colonization process of world of life) and transformers (resistence and confrontation process against colonization) that say about profissional artisanal fishing practice. We identified dialogically that elapse of this local social practices educational processes liberating, of announcement and permanent denunciations, established on internal solidarity, feature of traditional ethic of ribeirinha pantaneira (Pantanal natives). We also observed that researches of environmental education based on values, pratices and dialogical - critical concepts intend to potentize the coordenation of actions.
\end{abstract}

Keywords: Evironmental education dialogical-critical. Evironmental education at Pantanal. Evironmental education. Dialogical learning. Communicative-critical methodology

\footnotetext{
${ }^{1}$ Este artigo foi elaborado no contexto de exigências do Programa de Pós-graduação em Ciências Ambientais da Universidade Federal de São Carlos. A tese de doutorado da qual ele faz parte é composta de quatro artigos alinhavados entre si. Este trata dos processos educativos transformadores na prática da pesca tradicional; o segundo da participação das pescadoras/es na formulação das políticas públicas de pesca; o terceiro, discorre sobre os saberes tradicionais e a conservação da biodiversidade de peixes; e o quarto, apresenta os encaminhamentos e demais proposituras oriundas desta pesquisa que tratam das políticas públicas atinentes à pesca tradicional.

2Professor do IFMT Campus Cáceres - Olegário Baldo. Doutorando em Ciências Ambientais - UFSCar. Linha de pesquisa Ambiente e Sociedade - Educação Ambiental.

3Professor do Programa de Pós-graduação em Ciências Ambientais da UFSCar. Pós-doutorado em sociologia UFSCar. Coordenador do grupo de estudo e pesquisa em educação ambiental (Gepea / UFSCar)
} 
ISSN- 1413-8638

E-ISSN - 2238-5533

v. 22, n. 1, p. 111-131, 2017

\section{INTRODUÇÃO}

No Pantanal de Mato Grosso as comunidades tradicionais pesqueiras geram benefícios para toda a sociedade. Isso ocorre tendo em vista promoverem a manutenção da sociobiodiversidade pantaneira, através de modos próprios ser, fazer e se relacionar com o ambiente em que compartilham seu mundo da vida. $\mathrm{O}$ exercício da pesca profissional artesanal é uma atividade contra hegemônica ${ }^{4}$, pois, através da defesa da cultura pantaneira, enfrenta diariamente os interesses dos projetos políticos neoliberais, a exemplo do avanço do agronegócio - monocultura, latifúndios e agrotóxicos - e da implantação de usinas hidrelétricas - de pequeno, médio e grande porte - nos rios da Bacia do Alto Paraguai.

A pesca profissional artesanal ${ }^{5}$, como será demostrado nesse artigo, é essencialmente caracterizada por seu aspecto cultural. A tradição, materializada especialmente nos instrumentos e técnicas de pesca, representa uma expressão fundamental dos processos educativos intrínsecos às práticas sociais dessas comunidades. As/os pescadoras/es ${ }^{6}$ tradicionais têm nesse conhecimento tradicional, cunhado em sua memória coletiva, uma de suas principais fontes de informação, manutenção de sua cultura e conservação da biodiversidade. Seu cotidiano é caracterizado pela resistência e luta pela manutenção de seus territórios de pesca e da proteção do patrimônio cultural material e imaterial.

No município de Cáceres a pesca profissional artesanal é desenvolvida por pescadoras/es vinculadas/os a duas entidades: a Colônia Z-2 e a Associação de Pescadores Profissionais de Cáceres - Appec. São aproximadamente 800 filiadas/os à colônia e 400 filiadas/os à Appec. Em grande medida, esta atividade é desenvolvida de forma artesanal e ocorre majoritariamente no rio Paraguai e em seus afluentes. Nesta região a pesca é uma importante atividade humana, seja para subsistência, lazer ou econômica. Diferente da pesca de subsistência - que não permite a comercialização -, a/o pescadora/or profissional artesanal

\footnotetext{
${ }^{4}$ Nos termos gramischianos (GRUPPI, 1978), entendemos que há um movimento contra hegemônico nos enfrentamentos cotidianos empreendidos pelas/os pescadoras/es tradicionais no Pantanal de Mato Grosso, especialmente, no que trata da defesa de seus territórios de pesca e cultura.

5 Para este artigo as/os pescadoras/es profissionais artesanais serão identificadas/os como pescadoras/es tradicionais. Esta designação se deu em função do consenso construído acerca desse tema durante a pesquisa, a partir dos quais nossos diálogos levaram em consideração os aspectos culturais que caracterizam a atividade.

${ }^{6}$ Freire (2005) em "Pedagogia da esperança" desculpa-se com as mulheres por seus textos antigos e defende a ruptura da dominância do gênero masculino na língua portuguesa. Neste sentido, optamos por utilizar uma linguagem não sexista nesta pesquisa e neste texto, repercutindo um novo discurso democrático que vem se construindo nas últimas décadas nesse sentido. De acordo com o autor, "mudar a linguagem faz parte do processo de mudar o mundo... a relação entre linguagem-pensamento-mundo é uma relação dialética, processual, contraditória. É claro que a superação do discurso machista, como a superação de qualquer discurso autoritário, exige ou nos coloca a necessidade de, concomitantemente com o novo discurso, democrático, antidiscriminatório, nos engajarmos em práticas também democráticas." (p. 68).
} 
vende o seu pescado, que tem como destino principalmente o abastecimento da população local e regional.

Além de conhecerem os melhores locais de pesca a maioria dessas/es pessoas, ainda, possuem seus barcos, taboados, remos, motores etc., e somado a isso, em função de seus saberes de experiências feito (FREIRE, 2005), muitas/os delas/as dominam a arte da confecção de diversos apetrechos. Esse contexto de prática social (OLIVEIRA, et al. 2009) oportuniza o desenrolar de um processo educativo de fato transformador, pois o conhecimento do ambiente, a posse desses instrumentos e domínio dessas artes lhes confere autonomia para - pelos menos em parte - decidirem suas vidas diante das ameaças que diariamente lhes sobrevêm. .

Dialogando, então, sobre as práticas sociais pantaneiras e os processos educativos decorrentes, objetivamos identificar, em diálogo com pescadoras/es tradicionais, quais são os elementos obstaculizadores (que servem a processos de colonização do mundo da vida) e transformadores (que servem a processos de resistência e enfrentamento à colonização) que dizem respeito à prática da pesca profissional artesanal. Portanto, trataremos neste artigo dos processos educativos de enfrentamento e resistência que ocorrem nas práticas sociais pantaneiras, considerando, para tanto, as vozes das/os pescadoras/es profissionais filiadas/os às duas entidades de representação sediadas no município de Cáceres-MT.

\section{ASPECTOS TEÓRICOS QUE ORIENTARAM A PESQUISA SOCIEDADE DA INFORMAÇÃO E O GIRO DIALÓGICO NO PANTANAL DE MATO GROSSO}

Depois dessas nossas conversas o fiscal precisa me falar onde é que está escrito que eu não posso mais fazer isso ou aquilo [...]. Curimbatá ${ }^{7}$

As mudanças que ocorrem na sociedade contemporânea têm demonstrado que após os anos de 1970, esta sociedade tem se apresentado com diferentes denominações, tais como sociedade da informação, sociedade do conhecimento e a sociedade do risco (GÓMEZ et al. 2006). Para a autora e os autores,

em qualquer caso, estas diferentes concepções de sociedade compartilham um denominador comum, o diálogo, que se constitui uma nova categoria social inerente às relações sociais, influenciando em todos os âmbitos, tanto no econômico e político como no pessoal, familiar e social. (GÓMEZ et al., 2006, p. 11-12, grifo e tradução nossa)

\footnotetext{
${ }^{7}$ Consensuamos, durante a apresentação do termo de consentimento livre e esclarecido, que as/os pescadoras/es serão identificadas/os por codinomes. A maioria delas/es escolheram nomes de animais e plantas do Pantanal.
} 
ISSN- 1413-8638

E-ISSN - 2238-5533

v. 22, n. 1, p. 111-131, 2017

As formulações teóricas propostas por Castells (2005, v.1), somadas às contribuições elaboradas pelo Centro Especial de Investigação em Teorias e Práticas Superadoras de Desigualdade (Crea) da Universidade de Barcelona e pelo Núcleo de Investigação e Ação Social e Educativa (Niase) da Universidade Federal de São Carlos, nos mostram que a partir de então a informação passa a ser elemento central nas relações humanas, sejam elas educacionais, trabalhistas, comerciais, políticas etc. e, também, tem implicações geopolíticas, tanto no âmbito local quanto global, inaugurando um novo paradigma societário, o da sociedade da informação.

Diante disso, grupos de interesses diversos, especialmente os envolvidos em conflitos socioambientais (BURSZTYN, 2001; HARTMANN, 2001; LAYRARGUES 2006), como as pessoas com quem dialogamos, tendem a concentrar seus esforços na busca e processamento de informações com vistas a atender seus pleitos. Se, por um lado, setores de mercado impõem suas demandas, inclusive ocupando todas as instâncias do Estado - Judiciário, Executivo, Legislativo e o Ministério Público -, por outro, setores populares se articulam em movimentos não institucionalizados e/ou através de pessoas jurídicas de direito privado com fins de se oporem às condições de opressão às quais são submetidas/os. Ao tomarem conhecimento de seus direitos e deveres, aquelas/es que eram/são tidas/os como seres menos pelo projeto societário capitalista, além de ter a oportunidade de decidir sobre suas vidas, passam, do mesmo modo, a questionar de forma consistente as arbitrariedades cometidas pelo capital.

Há evidenciado, portanto, um giro dialógico (AUBERT et al., 2008, p. 33), a partir do qual as pessoas se informam e criticamente desvelam e analisam sua realidade. Diante desse processo passam, então, a questionar contratos, convenções e tratados, duvidar das imposições dogmáticas e da rigidez do pensamento (GADOTI, 2003, p. 16-23), questionar a burocratização e a instrumentação dos ambientes de aprendizagem pelas elites (GUTIERREZ, 1988, p. 17 - 46) e a problematizar o distanciamento das políticas públicas de sua realidade (FREIRE e NOGUEIRA, 1989). Portanto, como apontado por Flecha, Gómez e Puigvert (2001), o giro dialógico tem repercussão na vida cotidiana das pessoas - na relação entre familiares, amigas/os, trabalhadoras/es e empregadoras/es - e, além disso, tem oportunizado uma maior participação daquelas/es que tradicionalmente tiveram seu direito de dizer e agir cerceado.

\section{A AÇÃO DIALÓGICA E A PRÁXIS: SUPORTE, TRABALHO E OS ELEMENTOS ESSENCIAIS AO DIÁLOGO}


A teoria da ação dialógica - proposta por Freire na década de setenta (FREIRE, 2004) - está fundada no diálogo como sendo algo próprio da natureza humana. Freire e Shor (2001, p. 122-123) afirmam que o diálogo é "parte da natureza histórica dos seres humanos. [...]. O diálogo sela o relacionamento entre os sujeitos cognitivos, podemos, a seguir, atuar criticamente para transformar a realidade". Esta teoria apresenta o diálogo como nossa condição ontológica, apresenta-nos como seres que se humanizam enquanto dialogam para transformar a realidade. Posto isso, resta-nos a possibilidade de sugerir que a ação dialógica como aqui referida -, é que dá consistência ao giro dialógico. Não se trata algo dado pelas elites.

Não há de se esperar, portanto, que representantes do capital façam essa mudança; seria ingenuidade aguardar que essa redefinição de prioridades seja feita (de forma verdadeira) na direção de atender a pauta das/os excluídas/os. Como já dito por Freire (1996, p.55) não há "nenhuma vinculação dialogal entre estas elites e estas massas [...]". Diante disso, sustentamos que, no compromisso com a luta por liberdade - por serem mais -, oprimidas/os devem, em solidariedade estabelecer agendas comuns com seus semelhantes e com as/os diferentes.

A pesca tradicional é desenvolvida em um lugar no mundo, neste caso as águas no Pantanal de MT. Para os demais seres da natureza o Pantanal é suporte. Nele os seres vivos não humanos imprimem seu instinto, mas não deliberam contra suas aptidões inatas, são adaptativos. Seres humanos, pelo contrário, não permaneceram no instinto, mas objetivam a realidade, deliberam sobre as circunstâncias da vida, são transformadores. Freire (2004) nos mostra que para o ser humano o mundo é uma realidade objetiva, possível de ser conhecida e transformada. Assim, o Pantanal com todas as suas contradições compõe o mundo da vida daquelas/es que exercem a pesca tradicional. Como trabalhadoras/es, estas pessoas têm consciência de luta, do tempo, do espaço, fazem cultura, temporalizam-se, fazem-se humanos de um local para o mundo e de um instante para a história sempre em um movimento dialético; transformam o suporte em mundo através do trabalho. Freire (1992) considera que

somente o homem, como um ser que trabalha, que tem um pensamentolinguagem, que atua e é capaz de refletir sobre si mesmo e sobre a sua própria atividade, que dele se separa, somente ele, ao alcançar tais níveis, se fez um ser da práxis. Somente ele vem sendo um ser de relações num mundo de relações. Sua presença num tal mundo, presença que é um estar com, compreende um permanente defrontar-se com ele (FREIRE, 1992 p. 39 grifo do autor)

Para nós, o trabalho ao lado do diálogo é condição ontológica, através dele as pessoas produzem sua própria existência interagindo com a natureza e com os outros seres humanos e, 


\section{AMBIENTE \& EDUCAÇÃO \\ ISSN- 1413-8638 \\ E-ISSN - 2238-5533 \\ v. 22, n. 1, p. 111-131, 2017}

assim, produzem conhecimentos. Como dito é através dele que os sujeitos agem no suporte transformando-o em mundo, é em trabalho que o ser humano cria consciência da história e cultura. Para as pessoas livres o trabalho é voluntário, elas decidem de que maneira intervir na natureza, moldam seu mundo, se humanizam enquanto fazem isso porque são livres para fazêlo. Além disso, não desconhecem a liberdade das outras, antes, dialogam sobre como farão essa intervenção.

Nesse interim, como analisado por Lukács (1978), na sociedade capitalista o trabalho perde esse sentido, ele deixa de ser livre, prazeroso. Nela ele é transformado em trabalho assalariado, em mercadoria; ao perder os meios de produção/subsistência a/o trabalhadora/or é alienado da atividade produtiva e consequentemente do produto, fruto de sua ação no mundo. Processos de pesquisa dialógicos propõem interferir nessa relação, objetivam problematizar, em diálogo, as formas de interação entre os seres humanos e entre eles e a natureza, objetivando, portanto, superar as formas de opressão que advém dessa forma de interação.

\section{AGIR COMUNICATIVO: COMUNICAR PARA TRANSFORMAR A REALIDADE}

Jürgen Habermas, através da teoria do agir comunicativo, publicada nos anos de 1980 (HABERMAS, 2012a e 2012b), parte da compreensão de que vivemos em uma sociedade dual, que a estrutura dessa sociedade é composta pelo mundo da vida e pelo sistema. Para ele, a realidade social é uma elaboração humana que não depende do significado que as pessoas, particularmente, atribuem ao mundo, mas sim dos significados construídos intersubjetivamente.

O mundo da vida constitui o âmbito de atuação das pessoas, interativamente: a efetivação da agência humana; é formado pela coexistência de três mundos: o mundo objetivo refere-se à totalidade das coisas sobre as quais os seres humanos podem emitir enunciados pretensamente verdadeiros e buscar entendimento sobre eles; o mundo social refere-se à totalidade das relações sociais que, tácita ou normatizadamente, referem a legitimidade de comportamentos pretensamente corretos em interações interpessoais; por sua vez, o mundo subjetivo diz respeito à totalidade das vivências às quais somente a/o falante tem acesso privilegiado e que ela/ele pode manifestar de modo pretensamente veraz a uma outra pessoa ou a um grupo. De outro lado, o sistema constitui o âmbito institucional de administração, organização e regulação da vida em sociedade. Há evidentemente uma imbricação entre mundo da vida e sistema: de um lado, são também pessoas que efetivam a existência e a atuação do sistema e, de outro, as pessoas em seus mundos da vida de convivência cotidiana 
são também afetadas diretamente pelo sistema. Em princípio, para o autor, o mundo da vida é marcado prevalentemente pela busca do entendimento e, por sua vez, o sistema é marcado prevalentemente pela busca do êxito.

Em sociedades de classes, como a nossa, há uma progressiva desacoplagem entre o sistema e o mundo da vida. Para o autor, ocorre um avanço da colonização do mundo da vida pelo sistema, na medida em que a burocratização (do Estado) e o dinheiro (do mercado) tomam espaços que antes eram ocupados pela solidariedade como princípio de tomada de decisão, inclusive no âmbito familiar e no comunitário. Com esse processo, ações comunicativas que objetivam a coordenação de ações transformadoras a partir da busca do entendimento, são substituídas por ações orientadas pelo êxito, o que acaba por gerar patologias sociais.

Diante disso, com vistas a enfrentar estas patologias, Habermas afirma que, para além das ações estratégicas, teleológicas, dramatúrgicas, deve ser adotado o agir comunicativo. Neste, as pessoas capazes de fala e ação, que estabelecem relações interpessoais - seja por meios verbais ou extra verbais - podem alcançar objetivos pela via do entendimento (tendo o êxito como uma decorrência do entendimento e não como uma orientação a priori), de forma que através dele, do entendimento, seja possível coordenar os planos de ação decorrentes de um processo interativo e suas respectivas execuções. Para Habermas (2012) o conceito de entendimento remete a

um comum acordo almejado pelos participantes e racionalmente motivado, que se mede segundo pretensões de validade criticáveis. As pretensões de validade (verdade proposicional, correção normativa e veracidade subjetiva) caracterizam diferentes categorias de um saber que se corporifica simbolicamente em exteriorizações. (Habermas, 2012, v. 1, p. 147)

Posto isso, não se deve reduzir a compreensão sobre comunicação a simples conversação, que, por isso, se resuma apenas a expressar ou a interpretar a realidade. Deve ir além, precisa ser uma forma de organização da ação, tem de ser um agir comunicativo, tem que ser práxis. Habermas introduz com isso "o entendimento linguístico enquanto mecanismo da coordenação da ação" (HABERMAS, 2012a, p. 182). Note-se que, nesse sentido, a

\footnotetext{
racionalidade comunicativa em maior medida, por sua vez, amplia no interior de uma comunidade de comunicação o espaço de ação estratégica para a coordenação não coativa de ações e a superação consensual de conflitos de ação [...]. (HABERMAS, 2012a, p. 43).
}

Diferente da racionalidade instrumental, a racionalidade comunicativa possibilita que as/os falantes coordenem seus atos através de uma ação comunicativa pautada, substancialmente, nas pretensões de validade (verdade, correção e veracidade), visando a 
ISSN- 1413-8638

E-ISSN - 2238-5533

v. 22, n. 1, p. 111-131, 2017

coordenação de ações e a superação das situações de opressão. Há, nos contextos de busca de entendimento para coordenação de ações, uma coação a partir do melhor argumento (HABERMAS 2012a, p. 67), não uma imposição de ideias fundada no poder e/ou na manipulação perlocutiva que vise majoritariamente o êxito.

Consideramos que nas situações de conflitos socioambientais sobre as quais estamos debruçados neste artigo, apesar da permanente ingerência do Estado e do mercado, há no interior das comunidades tradicionais envolvidas, movimentos solidários internos que irrompem resistentemente às tentativas de colonização impostas ao seu mundo da vida. Diante disso, essa pesquisa de educação ambiental lançou mão de uma metodologia que, consubstanciada nestes referenciais teóricos, permitiu ao grupo de pessoas participantes, além de identificar os elementos que obstaculizam os processos de libertação, também, viabilizar ações de enfrentamento e superação das situações limites em que vivem cotidianamente implicadas.

\section{CONSIDERAÇÕES METODOLÓGICAS E DELINEAMENTO DA PESQUISA}

Para a realização dessa pesquisa de educação ambiental dialógico-crítica (LOGAREZZI, 2009, 2010; 2012), utilizamos a metodologia comunicativo-crítica - MCC (GÓMEZ et al., 2006), que é fundada na ação dialógica de Freire, no agir comunicativo de Habermas e na aprendizagem dialógica de Flecha (1997). A MCC é comunicativa porque "supera a dicotomia objeto/sujeito mediante a categoria da intersubjetividade e crítica (em consistência com a metodologia sociocrítica) porque parte da capacidade de reflexão e autorreflexão das pessoas e da sociedade" (GÓMEZ et al., 2006, p. 12, tradução nossa). Nela, considera-se respeitosamente a voz de todas/os as/os envolvidas/os no processo investigativo, de modo a não haver desnível epistemológico e nem hierarquia interpretativa entre participantes de diferentes inserções sociais/culturais. Com isso, distinguem-se os papéis de pesquisador/a acadêmico/a e de pesquisador/a do contexto da pesquisa, ou popular, cujo encontro potencializa a produção do conhecimento dialógico, em que a elaboração teórica e a vivência prática interagem dialógica e dialeticamente, resultando numa práxis transformadora comprometida com os desafios aportados pelas pessoas do contexto, redundando ainda na perspectiva de coletivamente se fazerem sujeitos históricos. Destaca-se que a distinção entre esses papéis não implica a admissão daquele desnível ou daquela hierarquia. $\mathrm{Na}$ verdade, implica maior rigor na produção do conhecimento, na medida em que se aliam sistematização teórica acadêmica e contextualização prática popular. 
Para que de fato este processo investigativo "comunicativo-crítico" seja implementado na pesquisa, Flecha (1997) apresenta os princípios da aprendizagem dialógica que devem se fazer presentes no processo: diálogo igualitário, inteligência cultural, transformação, dimensão instrumental, criação de sentido, solidariedade e igualdade de diferenças. Objetivando estabelecer uma aproximação teórico-metodológica entre uma educação ambiental crítica e esses princípios, Logarezzi (2010) considera que o qualificativo crítica

inclui a denúncia das contradições sociais enquanto base da destruição ambiental [...]. Por sua vez, o qualificativo "dialógica" indica, também na concepção freiriana, que no fundamento do processo educativo estão a incompletude humana e a tomada de posição frente ao real, como ontologia e base da educabilidade [...]. (LOGAREZZI, 2010, p. 14)

Quanto às técnicas de coleta de dados, Gómez et al. (2006) afirmam que podem ser utilizadas tanto formas quantitativas quanto qualitativas, ressalvando que sejam orientadas por uma perspectiva dialógica, haja visto a natureza e a dimensão do que se investiga. Para tanto, nessa pesquisa foram utilizados a observação comunicativa, a entrevista em profundidade e o grupo de discussão comunicativo. (p. 77-89)

Assim como nas demais fases do projeto, as pessoas envolvidas em cada etapa do processo investigativo participaram ativamente da fase de análise dos dados, consolidando a ruptura com os desníveis epistemológicos e interpretativos. Diante disso, procuramos identificar duas dimensões presentes na realidade dessas pessoas: a obstaculizadora - que configura barreiras que impedem ou dificultam a efetivação de maior igualdade social -, e a transformadora - que mostra as formas ou os caminhos de superação dessas barreiras. Por exemplo, as/os pescadoras/es que participaram das entrevistas, além de validarem as transcrições, concomitantemente, analisaram os dados a partir destas dimensões de análise. Participaram de forma direta das atividades educativas 83 pessoas, sendo 25 pescadoras e 58 pescadores, vinculadas às duas instituições de representação (Colônia Z-2 e Appec). Durante a observação comunicativa dialogamos com 71 pessoas, na entrevista em profundidade com 40 pessoas e nos grupos de discussão comunicativos (GDC) com 16 pessoas ${ }^{8}$. Todas as pessoas que participaram das entrevistas em profundidade e dos grupos de discussão comunicativos assinaram termo de consentimento livre e esclarecido aprovado pelo comitê de ética da Ufscar.

\footnotetext{
${ }^{8}$ Os GDC trataram dos seguintes temas: a) registro de saberes tradicionais e inclusão de sua história nos currículos das escolas municipais; b) a política municipal de pesca; c) a questão territorial: participação no processo de discussão sobre o Plano de Manejo da ESEC de Taiamã e a demanda pela Unidade de Conservação de Uso Sustentável; e d) áreas de uso restrito sob o olhar das/os pescadoras/es profissionais artesanais subsídios ao Cadastro ambiental rural (CAR).
} 
ISSN- 1413-8638

E-ISSN - 2238-5533

v. 22, n. 1, p. 111-131, 2017

As informações foram diariamente registradas em um diário de campo e organizadas em matrizes de análise dispostas em temas, categorias, subcategorias e dimensões. Esses dados são de natureza complexa e foram sistematizados em quadros ${ }^{9}$ baseados no esquema do quadro 1. Essa complexidade implica alguma imprecisão ou ambivalência da localização de certos dados nas células do quadro. Todavia nos esforçamos para, em diálogo com cada participante, localizar em suas falas elementos que possam ser identificados de acordo com a temática do exercício da pesca tradicional, com as categorias mundo da vida e sistema, com as subcategorias sujeito, Colônia Z-2/Appec, Estado e mercado e, por fim, com as dimensões obstaculizadora e transformadora, que se cruzam nas respectivas células indicadas no quadro 1.

Quadro 1 - Sistematização geral dos dados referentes à temática do exercício da pesca profissional artesanal

\begin{tabular}{|c|c|c|c|c|}
\hline \multirow{2}{*}{ Dimensões } & \multicolumn{4}{|c|}{ Tema, categorias e subcategorias } \\
\cline { 2 - 5 } & \multicolumn{4}{|c|}{ Exercício da pesca tradicional pantaneira } \\
\cline { 2 - 5 } & Sujeito & $\begin{array}{c}\text { Colônia Z-2 / } \\
\text { APEEC } \\
\text { representação }\end{array}$ & Estado & Mercado \\
\cline { 2 - 5 } & EOMs & EOSr & EOSe & EOSm \\
\hline \hline Obstaculizadora & ETMs & ETSr & ETSe & ETSm \\
\hline Transformadora & & & & ETs \\
\hline
\end{tabular}

A primeira letra da sigla se refere ao tema $(\mathrm{E})$, a segunda à dimensão $(\mathrm{O}$ ou $\mathrm{T})$, a terceira à categoria $(\mathrm{M}$ ou $\mathrm{S})$ e a quarta à subcategoria $(\mathrm{s}, \mathrm{r}, \mathrm{e}, \mathrm{m})$.

\section{PROCESSOS INVESTIGATIVO-EDUCATIVOS DE RESISTÊNCIA NA PRÁTICA DA PESCA PROFISSIONAL ARTESANAL: O EXERCÍCIO DA PESCA TRADICIONAL}

Nós vivemos é no acampamento, lá nós dormimos com um olho fechado e outro aberto, porque se não o turísta isca nosso anzol, toma nosso ponto, por isso que nós precisamos de uma reserva. Cachara [EOSm]

$\mathrm{Na}$ esteira do que refletimos a partir do referencial teórico desse texto, especialmente apontado por Freire, Habermas e Flecha, o diálogo e a confiança foram elementos centrais das nossas interações. Como fora indicado, aqui são consideradas as vozes de todas as pessoas, não há desnível epistemológico e nem hierarquia interpretativa; e é no encontro dos saberes acadêmicos - responsabilidade do pesquisador e colaboradoras/es - com os saberes

\footnotetext{
${ }^{9}$ Foi sistematizado um quadro para cada tema - neste artigo, tratamos particularmente do tema do exercício da atividade pesqueira tradicional. Na pesquisa mais ampla, surgiram ainda outros temas: o da participação, da conservação da biodiversidade de peixes e do processo de transformação vivenciado pelas pessoas.
} 
tradicionais que se dá a produção do conhecimento dialógico pretendido nessa pesquisa, de cujas interações resultam ainda efeitos educativos transformadores e emancipadores dos sujeitos implicados.

Em meio a um conjunto mais amplo de dados produzidos e sistematizados coletivamente $^{10}$, recortamos para este artigo, parte daqueles referentes ao tema do exercício da pesca profissional artesanal, cujos elementos foram identificados com códigos (de quatro letras) e alocados nas respectivas células do quadro 1. Com base neste conjunto de elementos empíricos assim organizados, o tema foi analisado por meio de quatro subtemas, conforme segue.

\title{
A DESESPERANÇA: DESVELAR A REALIDADE MEDIATIZADORA PARA ENFRENTAR AS SITUAÇÕES LIMITE
}

Um dos elementos obstaculizadores adstritos ao mundo subjetivo destas pessoas, sobre o qual nos debruçamos longamente, foi a desesperança. Muitas/os profissionais estavam abandonando o exercício da profissão ${ }^{11}$ em função da falta de diálogo do Estado para a formulação de políticas de pesca (proibição do uso de apetrechos, seguro defeso etc.) e, também, por causa da insignificância/inexistência das políticas de fomento e assistência técnica. Eu não tenho esperança, não acredito que alguma coisa vai melhorar, os políticos não se preocupam com a nossa categoria e com os peixes [...] Curimbatá [EOMs]; Se continuar assim minhas filhas vão passar fome eu não tenho mais fé nessa nossa vida. Chuncha [EOMs].

Ao lado dos relatos de Curimbatá e Chuncha, registramos muitos outros que expressam os sentimentos daquelas/es que já pretenderam ou pretendem abandonar atividade. Diante de alegações como estas procuramos apresentar a esperança como necessidade ontológica do ser humano, dialogamos sobre o esperançar freiriano. Além disso, a partir dos exemplos, abordamos a desesperança como consequência de intromissões estatais descontextualizadas da realidade local. Como ensinado por Freire (2002)

\begin{abstract}
É preciso ficar claro que a desesperança não é maneira de estar sendo natural do ser humano, mas distorção da esperança. Eu não sou primeiro um ser da desesperança a ser convertido ou não pela esperança. Eu sou, pelo contrário, um ser da esperança que, por "n" razões, se tornou desesperançado. Daí que uma das nossas brigas como seres humanos deva ser dada no sentido de diminuir as razões objetivas para a desesperança que nos imobiliza. (FREIRE, 2002, p. 29)
\end{abstract}

\footnotetext{
${ }^{10}$ Nesta pesquisa tratamos de três temas: exercício da pesca profissional artesanal; participação nos processos políticos e conservação da biodiversidade de peixes.

${ }^{11}$ Apesar de muitas/os abandonarem o exercício da profissão, mas continuam preenchendo as declarações de pesca para fins de garantir os direitos trabalhistas e previdenciários.
} 
ISSN- 1413-8638

E-ISSN - 2238-5533

v. 22, n. 1, p. 111-131, 2017

Durante este processo dialógico procuramos argumentar que as $n$ razões que geram desesperança não são resultado do acaso, mas consequência das ações/inações de um Estado e de um mercado que não priorizam a categoria. Um dos exemplos que utilizamos em diversos ambientes de diálogo foi o apontado pela pescadora Mutum e pelo pescador Piquira. Trata-se da proposta de moratória da pesca feita pelo Blairo Maggi através do Projeto de Lei do Senado 750/2011. Como salientado por Tavolaro (2005), práticas de educação ambiental devem estar atentas às "cadeias de ação e às redes de poder envolvidas nos processos de tomada de decisão" (p. 22). Assim sendo, nas reuniões dos GDC problematizamos as questões relativas às redes e cotas de poder das/os agentes de mercado dentro das estruturas do Estado e a importância da mobilização e participação delas/es no sentido de desvelarem, por exemplo, os interesses da indústria aquícola; o avanço da indústria energética nos rios da BAP etc.

\section{CONFIANÇA E SOLIDARIEDADE INTERNA: CONDIÇÕES DE SOBREVIVÊNCIA}

Pescadoras/es profissionais que realmente vivem da atividade artesanal são solidárias/os e confiam suas vidas umas/uns às/aos outras/os. A solidariedade é outro elemento constituinte da aprendizagem dialógica (Flecha, 1997), bastante presente no cotidiano da pesca tradicional. É notório o quanto o companheirismo é presente na vida coletiva dessas pessoas, trata-se de uma característica fundante do mundo social delas/es. Ressalte-se que, a solidariedade se dá, principalmente, entre os pares - por isso a chamamos de solidariedade interna - entre as/os companheiros/as de pesca, entre aquelas pessoas que geralmente acampam-se próximas umas das outras e/ou participam da rede solidária de prática e comercialização do pescado.

Esta solidariedade de existires é marcada pelo cuidado e respeito recíprocos, característicos de uma ética tradicional ribeirinha pantaneira. É muito comum elas/es: compartilharem o acampamento/barraco, o alimento, as tralhas, combustível, ratearem os custos da pescaria, auxiliarem as/os companheiras/os a completar suas cotas semanais de pesca, dialogarem sobre a movimentação de cardumes, a circulação da fiscalização, o estoque pesqueiro de sua rede solidária de comercialização, etc. Há uma rede complexa de relações solidárias que dá sustentação ao mundo social na pesca artesanal. O pescador Pintado afirma sempre que: nossa vida aqui no rio é diferente da vida lá da cidade, aqui a gente tem outros jeitos de viver [ETMs]. Há, entre elas/es, acordos de convivência muito específicas que caracterizam o enfrentamento à colonização de seu mundo da vida. Nas palavras do pescador Pataquinha: muitas vezes o pescador não desiste da pescaria porque os amigos não deixam, 
um ajuda mesmo o outro, ajuda na cota, na gasolina, para levar o gelo, eu já ajudei companheiro assim. [ETMs]

Diante da precariedade da infraestrutura e carência de logística das entidades, falta de políticas de fomento e assistência técnica, a solidariedade interna torna-se condição de sobrevivência dessas pessoas. A solidariedade de gênero é outra característica marcante nas relações de trabalho. Nessa região, a atividade foi exercida durante muito tempo, majoritariamente, por homens. Entretanto, nos últimos 10 anos, o número de mulheres filiadas à Colônia Z-2 e da APPEC aumentou significativamente. Dados das agremiações dão conta de que aproximadamente $30 \%$ das/os membros são mulheres. Estas mulheres afirmaram que exercem a pesca profissional, especialmente porque amam o rio. Outro argumento diz respeito aos aspectos comerciais da atividade, já que várias delas pescam com seus parceiros, assim otimizam a captura e, consequentemente, minimizam os custos da atividade. Disseram que entre elas/es no dia a dia, seja na pesca, nas atividades culturais ou nas reuniões administrativas da Colônia Z-2 ou da APPEC, não há preconceito. Entretanto, afirma que ainda há muito preconceito na convivência com algumas/uns pescadoras/es amadoras/es e com pessoas do comércio local. Foram vários os relatos de pescadoras que já foram humilhadas por amadoras/es, em consultas médicas ou no comércio local quando falaram que eram pescadoras. No rio todo mundo é pescador, todo mundo é igual, tem todo um respeito. Nós fazemos de tudo que os homens fazem. Flor de Aguapé [EMTs]; Conquistamos respeito nesse rio porque nós fazemos a mesma coisa que estes homens fazem. Nós iscamos pendurão durante a noite [...] Imas na hora de vender os caras perguntam, foi você mesma que pegou? Aí eu fico [...]. Onça [EMTs]

Este ambiente solidário e enfrentante foi muito profícuo para o desenvolvimento de atividades educativas transformadoras que trouxeram à baila os contrastes existentes entre o modelo de desenvolvimento capitalista pretendido pelos agentes de mercado que interferem nos modos de produção e o de desenvolvimento solidário efetivado no árduo dia a dia da pesca tradicional. Ressalte-se também que, outra temática identificada e problematizada à luz do giro dialógico (AUBERT et al., 2008) que merece aprofundamento, diz respeito à divisão social do trabalho. Algumas pescadoras relataram que seus companheiros, apesar de solidários na prática pesqueira, não as ajudam nas atividades domésticas. Nos encontros em que este tema era suscitado, prevalecia um silêncio explicitamente denunciante, especialmente por parte das pescadoras mais antigas. Ao contrário disso, as mais jovens, sempre argumentavam que não concordavam com essa realidade e que seus companheiros tinham por 
obrigação ajudá-las, também nas atividades domésticas. Rosa afirmou que: eu faço tudo lá no rio com ele e ele sabe que eu chego cansada igual ele, então ele tem que me ajudar aqui em casa também; Chuncha discorreu longamente sobre os acordos que tem firmado com seu esposo sobre a distribuição das atividades domésticas: nós conversamos [...] ou nós fazemos tudo junto ou eu vou procurar outra profissão lá na fazenda.

\section{AMEAÇAS AO TERRITÓRIO E À CULTURA PANTANEIRA: O REGISTRO DE SABERES}

Expulsaram nós de lá da nossa terra! Mas o coração da minha família ficou lá [...]. Ferreirinha [EOSm]

Como apontado por Diegues (1983, 1988, 2002) a questão territorial não depende somente do tipo do meio físico utilizado por populações tradicionais, mas também das relações sociais existentes. Notamos que em função das condições ecológicas da região regidas pelo pulso de inundação - para as pescadoras/es tradicionais que atuam nos rios do Pantanal norte o território é dinâmico ${ }^{12}$, o movimento das águas dita seu modo de vida e consequentemente a ocupação dos melhores locais de pesca. O tradicional movimento que elas/es realizam na busca do pescado, somente tem sido garantido até hoje, em função do respeito que existe entre elas/es. Como já dito há, no mundo social, dessas pessoas, uma ética tradicional ribeirinha pantaneira entretecida em sua historicidade, a partir da pluralidade de sentidos que elas e eles dão a sua coexistência com o Pantanal. Durante nosso encontro de validação dos dados da observação comunicativa o pescador Ariranha argumentou que

todos que estão aqui já sabem até o jeito do companheiro chuçar o pendurão; cada um de nós temos a marca de nosso peixe, já sabemos onde é que cada um fica em cada época do ano [...] entre nós não tem problema, mas tem muito amador e turista que não respeita nossa história. Ariranha [ETMs]

Ao longo do processo interativo da pesquisa restou-nos evidente que a manutenção dos aspectos culturais constitui condição fundamental para o exercício da atividade pesqueira profissional. Diante disso, todas as ações que de alguma forma ameaçam a manutenção do

\footnotetext{
12 Adotamos o conceito de territórios tradicionais da Política Nacional de Desenvolvimento Sustentável dos Povos e Comunidades Tradicionais, como previsto no artigo $3^{\circ}$, II os espaços necessários a reprodução cultural, social e econômica dos povos e comunidades tradicionais, sejam eles utilizados de forma permanente ou temporária [...]. Nossa opção reside no fato de que esse conceito, além de ser fruto de um amplo processo dialógico do qual estes povos e comunidades participaram, também expressa o caráter da temporalidade, característicos dos territórios das/os pescadoras/es artesanais com quem dialogamos.
} 
caráter artesanal da atividade, devem ser cotidianamente problematizadas nos processos interativos, para que a partir da coordenação das ações, sejam enfrentados sistematicamente.

Os relatos delas/es apontam para o fato de que a proibição algumas técnicas de pesca é uma forma de fragilizar a categoria e, consequentemente, de retirá-las/os de seus territórios. Parte das mobilizações que têm sido realizadas pela categoria junto às instituições estatais diz respeito à manutenção de espaços territoriais tradicionalmente ocupados por estas pessoas para a implantação de seus acampamentos/barracos, a fixação de armadilhas e também a luta pela permanência do uso de alguns apetrechos. Nas palavras do pescador Dourado: "disso tudo que nós estamos fazendo, o mais importante é nossa cultura, nosso apetrecho e nosso lugarzinho pra pescar. É disso que nós precisamos!" [ETMs]

O ecossistema pantaneiro em toda sua complexidade de redes de interação, não se resume a espaço geográfico, não é somente suporte, mas, sobretudo, base material onde são entretecidos processos socioterritoriais. Trata-se do mundo objetivo a partir de onde elas/es emitem enunciados e intersubjetivamente interpretam sua realidade. Como apontado por Da Silva e Silva (1995), é no ritmo das águas que a cultura dessas comunidades tem sido elaborada. No Pantanal estão os territórios de pesca destas comunidades. Aqui elas/es têm, além de principal ambiente laboral, também seus lugares de abrigo, de desenvolvimento do imaginário mitológico, fazendo da vivência ali fonte de cultura e lazer onde são elaborados e reelaborados saberes tradicionais que lhes garantem a sobrevivência respeitosa com o ambiente há séculos.

\section{COMERCIALIZAÇÃO DO PESCADO: A AÇÃO PERMANENTE DAS/OS ATRAVESSADORAS/ES E A INAÇÃO PROPOSITẢDA DO ESTADO}

A dificuldade de comercialização do pescado foi apontada como um dos principais obstáculos a serem superados pela categoria. Para elas/es a ação das/os atravessadoras/es ocorre justamente porque não há uma política consistente de incentivo e fomento. É evidente a ação do mercado, no sentido de desarticular as relações diretas de comercialização entre as/os produtoras/es e as/os consumidoras/es. Para a pescadora Flor de Aguapé "Esse negócio do atravessador só vai acabar quando o governo olhar para nós e ver que nós também somos gente, não é só apoiar o plantador de soja, tem que apoiar nós os pequenos também." [EOSe]

Diante dos problemas financeiros é comum as/os profissionais recorrerem a estas "gentes do dinheiro". Atravessadoras/es, além de negociar as Declarações de Pesca Individual (DPI) e "comprarem" o seguro defeso, auxiliam as/os pescadoras/res subsidiando a aquisição 
ISSN- 1413-8638

E-ISSN - 2238-5533

v. 22, n. 1, p. 111-131, 2017

de apetrechos, de gelo e de combustível, além da aquisição, reforma e confecção de embarcações, segurança e informação com respeito ação da fiscalização; mas para isso fazem a "agiotagem do peixe", exigindo que o pagamento do empréstimo e/ou da informação sejam feitos em pescado e, mais grave que isso, são as/os atravessadoras/es que decidem o valor a ser pago. Tal gravidade aparece explicitadamente em relatos como os de Rubafo.

A gente não tem o que fazer, nós somos igual escravos, você vai lá, pega o dinheiro [empréstimo necessário para a operação de pesca], mas depois tem uns deles que só querem receber em peixe, você vai fazer o que, dá o peixe [em valores definidos/as pelas/os atravessadoras/es] e já volta para o rio [...] a pescaria estava fraca e minha família passou fome por causa disso. Rubafo [EOSm]

Ainda em relação as ações do mercado, como também foi identificado por Rieder, Maquêa e Castrillon (2001), Girard (2002), Calheiros et al. (2009), dialogamos sobre a luta dessas comunidades contra a implantação da hidrovia Paraguai-Paraná. Há um consenso de que a categoria deve permanecer mobilizada no sentido de enfrentar o retorno da navegação de barcaças sobre áreas de pesca - o que ocorria quando da existência do porto fluvial de Cáceres, desativado desde 2009. Como dito por Caravaçu, pescadoras/es mais antigas/es conviveram com essa realidade durante muitos anos: "esses mais novos não vão saber falar disso, mas nós que enfrentamos essas barcaças podemos falar. Quantas vezes eu e os companheiros precisamos sair de onde estávamos pescando para essas chatas passarem. Nessa canoa nossa, ou sai ou afunda”. [EOSm]. Além disso, a construção de pequenas centrais hidrelétricas nos rios da BAP foi outro ponto sobre o qual dialogamos. Além dos impactos ambientais já causados pelos barramentos - interferência no pulso de inundação e na migração de peixes durante a piracema -, pescadoras/es do distrito do Limão têm sentido significativamente o efeito negativo das barragens sobre a pesca artesanal.

No que toca a ação/inação do Estado, elas/es apontaram que os principais problemas estão relacionados à fiscalização, ausência de políticas de fomento, assistência técnica, políticas de saúde e educação específicas para a categoria. Sinalizaram que mesmo com a presença de diversos órgãos a fiscalização é insuficiente e seletiva. Para elas/eles existe um grande número de pescadoras/es que atuam de forma irregular, especialmente, durante o período do defeso. Além disso ainda existem agentes de Estado que agem com truculência, desrespeitando direitos legalmente garantidos à categoria. A fiscalização é importante para proteger os peixes, mas tinha que ser com um trabalho educativo [...] não é só colocar a farda e sair maltratando a gente aí não. Nós somos direitos, aqui não é bandido não. Martim Pescador [EOSe]. 
Houve consenso quanto à necessidade de maior aproximação entre elas/es e as/os agentes de fiscalização, entretanto prevaleceu o dissenso quanto à viabilidade de realizarmos reuniões com a presença das/os agentes. Em todos os nossos encontros havia, notadamente, por parte das/os pescadoras/es mais antigas/os, um receio permanente no que diz respeito a estabelecermos uma linha de diálogo com os órgãos de fiscalização, principalmente Secretaria Estadual de Meio Ambiente (Sema) e Polícia Ambiental.

\section{ALGUMAS CONSIDERAÇÕES}

Como se observou as/os pescadoras tradicionais participaram comunicativamente de todas as etapas da pesquisa desenvolvidas até este momento. Desde a identificação dos temas centrais, das políticas públicas acerca das quais nos debruçaríamos, dos locais e horários de encontros, etc. Estabelecemos dialogicamente nossas agendas, procuramos - considerando sempre as nossas diferenças e proximidades epistemológicas - respeitar a pluralidade de dimensões existente em nossas interações.

Para elas/es o Pantanal é o mundo das relações interpessoais e das interações a natureza em sua completude. Não é somente suporte, mas, diferente do que propõem o mercado e alguns agentes públicos, o Pantanal não se resume a fonte de emprego e renda, mas é, sobretudo, fonte de vida. Essa região é, a partir de sua heterogeneidade ecológica, o ambiente que mediatiza suas relações interpessoais, lhes dá sentido à existência, a partir de onde as/os trabalhadoras/es da pesca, de maneira dialógica - como em seus enfrentamentos cotidianos - expressam as dimensões simbólicas e indenitárias que lhes caracterizam como comunidades tradicionais.

Em face do que é proposto pelas teorias de Freire e Habermas, a metodologia comunicativo-crítica proporciona encontros e vivências em que pessoas dispostas/os a dialogar interpretam e reinterpretam seu modo de pronunciar o mundo. O encontro é verdadeiro, nasce a partir das intencionalidades de cada sujeito e se materializa na intersubjetividade da práxis, na palavra verdadeira que constitui o diálogo freiriano.

Por isso, a comunicação não pode se reduzir a verbalismos, com vistas somente a expressar ou interpretar as coisas e os fatos e da vida cotidiana. Ela deve desvelar a realidade, para coordenar ações que potencializem situações propositivas de transformação, com vistas a superar condições de opressão. Verificamos nestes anos de diálogo que isso somente é possível se de fato estiverem estabelecidos entre as/os participantes os laços de confiança que lhes permitirão lançar mão das pretensões de verdade que caracterizam o agir comunicativo. 
ISSN- 1413-8638

E-ISSN - 2238-5533

v. 22, n. 1, p. 111-131, 2017

Estas interações dialéticas - ser humano/ser humano e mundo social/ mundo objetivo - são origem e resultado das práticas sociais, não se trata de simplificação das relações, mas de uma postura epistêmica (que para nós é retorno ao que é ontologicamente ser humano) que reconhece que a origem do conhecimento está na intersubjetividade, reside necessariamente no encontro. Decorre disso, então, que os processos educativos - porque intersubjetivos podem ser conhecidos, criticados e potencializados no sentido da superação das situações de opressão, mediante ações educativas fundadas em princípios de uma ação dialógica (FREIRE, 2004).

Durante este processo educativo ambiental dialógico-crítica nos esforçamos por garantir que todas/os participassem comunicativamente de todas etapas da pesquisa. Não se tratou de doação e/ou tentativa de instrumentalizar acriticamente as comunidades, mas de encontro entre pessoas que pronunciam o mundo, entre os saberes tradicionais e a nossa contribuição com os saberes técnico-científicos objetivando o conhecimento dialógico.

Posto isso, além de mediar os encontros, foi de nossa responsabilidade argumentar a partir de informações técnicas - dimensão instrumental - sobre as questões apresentadas pelos sujeitos da pesquisa. Nesse movimento cooperativo de interpretação da realidade mediatizadora o esforço reside também, em descontruir o monopólio da fala e da ação. Para tanto, em todos os nossos encontros relembramos dialogicamente os elementos essenciais ao diálogo propostos por Freire (2004), a fim de, a partir deles, estabelecermos um diálogo verdadeiro - despido de hierarquias -, a partir do qual todas/os as/os pudessem argumentar livre e coordenadamente.

Além do processo educativo que se deu durante a realização dessa pesquisa, citamos, abaixo, alguns encaminhamentos já consensuados e direcionados para as representações e/ou para o poder público: a) proposta de que o preço mínimo a ser pago pelo pescado vendido para a colônia e para a associação, deve ser decidido em assembleia; b) parcerias com instituições públicas visando a promoção da cadeia produtiva; c) expediente à Sema com contribuições ao Cadastro Ambiental Rural; d) expediente à Sema solicitando a criação de uma unidade de conservação de uso sustentável; e) expediente ao Instituto Chico Mendes da Biodiversidade (ICMBio) com contribuições ao plano de manejo da Estação Ecológica de Taiamã e pedido de criação de uma unidade de conservação uso sustentável; f) expediente à Secretaria Municipal da Indústria, Comércio, Meio Ambiente e Turismo objetivando que o município promova uma política municipal de pesca e aquicultura com vistas a incluir a categoria nas discussões atinentes ao entreposto de pesca; g) expediente à Secretaria Municipal de Esporte, Cultura e Lazer objetivando que o município implemente o Registro de 
Bens Culturais de Natureza Imaterial; h) reuniões com a Secretária Municipal de Educação, a fim de propor que o município inclua no currículo escolar a história/cultura das/os pescadoras/es tradicionais; i) reunião com Núcleo de Economia Solidária da Universidade do Estado de Mato Grosso com vistas a promover diálogos entre as/os pescadoras/es sobre formas justas de comercialização.

Como dito, de início, não houve consenso em propostas que diziam respeito a expedientes que poderiam ser encaminhados às instituições de fiscalização, especialmente à Polícia Ambiental e à Sema. Também acordamos que os encaminhamentos propostos, ainda no início da pesquisa, que tratariam da questão das/os pescadoras/es de seguro, deveriam ser retomados em outros diálogos, para depois apresentarmos as propostas das comunidades ao poder público. Questões referentes a denúncias sobre pesca predatória, ação de atravessadoras/es e corrupção de agentes públicos também não foram consensuadas, mas permanecem abertas para que o grupo, se assim entender, possa oportunamente deliberar sobre elas.

\section{REFERÊNCIAS}

AUBERT, A. et al. Aprendizaje dialógico em la sociedade de la información. Barcelona: Hipatia, 2008.

BRASIL. Decreto no 6.040 de 7 de fevereiro de 2007. Institui a Política Nacional de Desenvolvimento Sustentável dos Povos e Comunidades Tradicionais. Disponível em: <http://www.planalto.gov.br/ccivil_03/_ato2007-2010/2007/decreto/d6040.htm>. Acesso em: $06 / 09 / 2013$

BURSZTYN, M. Políticas Públicas para o Desenvolvimento. In: A difícil sustentabilidade: política energética e conflitos ambientais. Rio de Janeiro: Garamond, 2001.

CALHEIROS, D. F. et al. Influências de usinas hidrelétricas no funcionamento hidro-ecológico do Pantanal Mato-Grossense -recomendações. Embrapa Pantanal. Documentos, 2009.

CASTELLS, M. Sociedade em rede. 8 ed., São Paulo: Paz e Terra. v. 1., 2005.

DA SILVA, C. J.; SILVA, J. A. F. No ritmo das águas do Pantanal. São Paulo: NUPAUB, 1995.

DIEGUES, A. C. S. Pescadores, camponeses e trabalhadores do mar. Editora Ática, 1983.

Mitos e realidades sobre pescadores artesanais. Programa de Pesquisa e Conservação de Áreas Úmidas no Brasil. Série Trabalhos e Estudos, 1988.

. (Org.) Povos e águas: inventário de áreas úmidas brasileiras. NUPAUB, 2002.

CATELLA, A.C. et al. Pesca: uma atividade estratégica para a conservação do Pantanal. Corumbá, MS: Embrapa Pantanal, Documentos. 2012. 3p. Disponível em: <http://www.cpap.embrapa.br/pesca/online/PESCA2012_CPAP1.pdf>. Acesso em: 10/06/2013 
AMBIENTE \& EDUCAÇÃO

ISSN- 1413-8638

E-ISSN - 2238-5533

v. 22, n. 1, p. 111-131, 2017

FLECHA, R. Compartiendo palabras. Barcelona: Paidós, 1997. . GÓMEZ, J. PUIGVERT, L. Teoría sociológica contemporánea. Barcelona: Paidós, 2001.

FREIRE, P. Extensão e comunicação? 10 ed. Rio de Janeiro: Paz e Terra, 1992.

. Educação como prática da liberdade. 22 ed. Rio de Janeiro: Paz e Terra, 1996.

. Pedagogia da autonomia. Saberes necessários à prática educativa. 25 ed. Rio de Janeiro: Paz e Terra, 2002.

. Pedagogia do oprimido. 38 ed. Rio de Janeiro: Paz e Terra, 2004.

Pedagogia da esperança: um reencontro com a pedagogia do oprimido. 12 ed. Rio de Janeiro: Paz e Terra, 2005.

NOGUEIRA, A. Que fazer: teoria e prática em educação popular. Petrópolis: Vozes, 1989.

SHOR, I. Medo e ousadia. O cotidiano do professor. 9 ed. Rio de Janeiro: Paz e Terra. 2001. GADOTI, M. Educação e poder. Introdução à pedagogia do conflito. 13 ed. São Paulo: Cortez, 2003. GIRARD, P. Efeito cumulativo das barragens no Pantanal. Campo Grande: Instituto Centro Vida, 2002.

GÓMEZ, J. et al. Metodologia comunicativa crítica. Barcelona: El Roure Editorial, 2006.

GUTIÉRREZ, F. Educação como práxis política. São Paulo: Sumus, 1988.

GRUPPI, L. O conceito de hegemonia em Gramsci. Rio de Janeiro: Graal, 1980.

HABERMAS, J. Teoria do agir comunicativo. v. 1. Racionalidade da ação e racionalização social. Tradução: Paulo Astor Soethe. São Paulo: WMF Martins Fontes, 2012a.

Teoria do agir comunicativo. v. 2. Sobre a crítica da razão funcionalista. Tradução:

Paulo Astor Soethe. São Paulo: WMF Martins Fontes, 2012b.

HARTMANN, W. D. Conflitos de pesca em águas interiores da Amazônia e tentativas de soluções. In: DIEGUES, A. C.; MOREIRA A. de C. C. Espaços e recursos naturais de uso comum. São Paulo: USP NUPALB, 2001.

LAYRARGUES, P. P. Educação para a gestão ambiental: a cidadania no enfrentamento político do conflitos socioambientais. In: LAYRARGUES, P.P.; LOUREIRO, C.F.B.; CASTRO, R.S. (Org.) Sociedade e meio ambiente: a educação ambiental em debate. $4^{\mathrm{a}}$ ed. São Paulo: Cortez, 2006.

LOGAREZZI, A. J. M. Discutindo a inteligência cultural diante da percepção socioambiental em contexto de comunidade de aprendizagem. In: Congresso Luso-afro-brasileiro de ciências sociais, 10², 2009, Braga, Portugal. Anais eletrônicos... Braga, Portugal: Universidade do Minho, 2009. CD ROM. p. 1-15.

Educação ambiental em comunidades de aprendizagem: uma abordagem críticodialógica. In: REUNIÃO ANUAL DA ANPED, 33a , 2010, Caxambu. Anais eletrônicos... Rio de Janeiro: Anped, 2010. CD-ROM.

. Educação ambiental crítico-dialógica em comunidades de aprendizagem. In: MATHEUS,

C. E. (Org.). Educação ambiental: múltiplos olhares e saberes. São Carlos: Rima, 2012. 
LUKÁCS, G. As bases ontológicas do pensamento e da atividade do homem. Temas de Ciências Humanas. v. 4, p. 1-18, 1978.

OLIVEIRA, M. W. et al. Processos educativos em práticas sociais: reflexões teóricas e metodológicas sobre pesquisa educacional em espaços sociais. 32ª . ANPED: 2009. Disponível em: < http://32reuniao.anped.org.br/arquivos/trabalhos/GT06-5383--Int.pdf>. Acesso em 10/05/2015 GIRARD, Pierre. Efeito cumulativo das barragens no Pantanal. Campo Grande: Instituto Centro Vida, 2002.

RIEDER, A.; MAQUEA, V.; CASTRILLON, S. I. K. A visão do homem pantaneiro sobre o Pantanal. In: Simpósio sobre os recursos naturais e socioeconômicos do Pantanal - os desafios do novo milênio. No 3, 2000, Corumbá - MS. Anais...Corumbá - MS: Embrapa, 200141 p.

TAVOLARO, S. B. F. Ação Comunicativa. In: FERRARO JUNIOR, L. A. (Org.). Encontros e caminhos: formação de educadoras (es) ambientais e coletivos educadores. v.1. Brasília: MMA, Diretoria de Educação Ambiental. p. 17-25. 